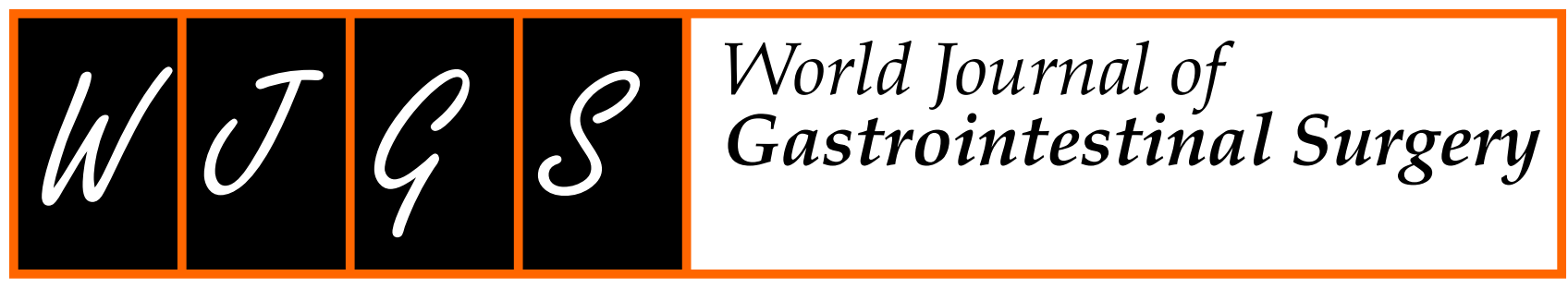

Submit a Manuscript: https:/ / www.f6publishing.com

World J Gastrointest Surg 2021 September 27; 13(9): 1050-1062

\title{
Quality of life after colorectal surgery: A prospective study of patients compared with their spouses
}

\author{
Gökçe Aylaz, Cihangir Akyol, Akın Fırat Kocaay, Derya Gökmen, Ayşe Burcu Yavuzarslan, Ayhan Bülent \\ Erkek, Mehmet Ayhan Kuzu
}

\section{ORCID number: Gökçe Aylaz 0000- 0002-9349-8359; Cihangir Akyol 0000-0002-3941-5268; Akın Firat Kocaay 0000-0002-6985-910X; Derya Gökmen 0000-0001-6266-3035; Ayşe Burcu Yavuzarslan 0000-0001-7880- 7910; Ayhan Bülent Erkek 0000-0002- 9041-341X; Mehmet Ayhan Kuzu 0000-0003-1561-9060.}

Author contributions: Aylaz G, Akyol C and Kuzu MA contributed to the study conception and design; Aylaz G, Kocaay AF, Yavuzarslan AB and Erkek AB contributed to the literature search and data extraction; Aylaz G, Gökmen D and Kuzu MA contributed to the acquisition, management, analysis and interpretation of data; Aylaz G, Kocaay AF and Akyol C drafted the manuscript; Kuzu MA and Akyol C critically revised the manuscript.

\section{Institutional review board} statement: The study was approved by the Ethics Committee of the Faculty of Medicine, Ankara University (21 September 2009, approval number: 06-82).

Clinical trial registration statement: This study is registered at ClinicalTrials.gov. The registration identification number is NCT04744792.
Gökçe Aylaz, Department of Surgery, Sisli Memorial Hospital, Istanbul 34385, Turkey

Cihangir Akyol, Akın Fırat Kocaay, Ayşe Burcu Yavuzarslan, Ayhan Bülent Erkek, Mehmet Ayhan Kuzu, Department of Surgery, Ankara University School of Medicine, Ankara 06100, Turkey

Derya Gökmen, Department of Biostatistics, Ankara University School of Medicine, Ankara 06100, Turkey

Corresponding author: Cihangir Akyol, FASCRS, FEBS, MD, Professor, Department of Surgery, Divison of Colorectal Surgery, Ankara University School of Medicine, Ankara 06100, Turkey.cihangirakyol@gmail.com

\section{Abstract}

\section{BACKGROUND}

Although radical surgery for colorectal cancer improves the oncological outcomes, a significant portion of patients suffer from alterations in their quality of life (QoL). There are many studies investigating the QoL of patients who have colorectal cancer but none of these focus on the QoL of spouses.

\section{AIM}

To compare the QoL of patients after colorectal surgery to the QoL of spouses.

\section{METHODS}

This prospective study consisted of patients who were married and who underwent surgery at the University of Ankara, Department of Surgery between March 2006 and November 2010. Patients' spouses were also enrolled. The study was approved by the Ethics Committee of the Faculty of Medicine, Ankara University, and all patients provided written informed consent. The study included patients who underwent curative surgery for colorectal carcinoma $[n=$ 100; abdominoperineal excision $(n=33)$, low anterior resection $(n=33)$, left hemicolectomy $(n=34)$ ] and their spouses $(n=100)$. The patients and spouses completed the Medical Outcome Study 36-item Short Form Survey (SF-36) and the World Health Organization Disability Assessment Schedule II (WHODAS-II) preoperatively and at postoperative months 15 to 18 .

RESULTS

During this 4.5-year study period, 273 patients with sigmoid or rectal cancer were 
Informed consent statement: All study participants, or their legal guardian, provided informed written consent prior to study enrollment.

\section{Conflict-of-interest statement:}

None of the authors have a conflict of interest.

\section{Data sharing statement: No} additional data are available.

\section{CONSORT 2010 statement: The} authors have read the CONSORT 2010 statement, and the manuscript was prepared and revised according to the CONSORT 2010 statement.

Open-Access: This article is an open-access article that was selected by an in-house editor and fully peer-reviewed by external reviewers. It is distributed in accordance with the Creative Commons Attribution NonCommercial (CC BY-NC 4.0) license, which permits others to distribute, remix, adapt, build upon this work non-commercially, and license their derivative works on different terms, provided the original work is properly cited and the use is non-commercial. See: htt p://creativecommons.org/License s/by-nc/4.0/

Manuscript source: Unsolicited manuscript

Specialty type: Gastroenterology and hepatology

Country/Territory of origin: Turkey

\section{Peer-review report's scientific quality classification}

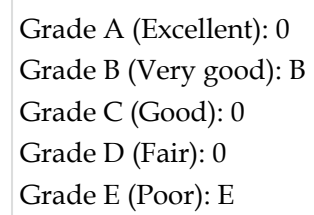

Received: March 25, 2021

Peer-review started: March 25, 2021

First decision: June 14, 2021

Revised: June 30, 2021

Accepted: July 29, 2021

Article in press: July 29, 2021

Published online: September 27, 2021 admitted to the hospital. Of these patients, 119 were eligible and willing to participate. Eleven patients had either systemic or locally inoperable disease, three patients had a severe surgical complication, and five patients were lost to followup. Therefore, a total of 100 patients completed the follow-up period. There was a statistically significant positive correlation between the disability scores of patients and the scores of their spouses for some of the WHODAS-II subscales, such as "self-care," "life activities," and "participation in society," as well as for the total WHODAS-II score. There was also a positive correlation between the QoL of patients and the QoL of their spouses in most of the SF-36 subscales. Statistically significant correlations were observed for the "bodily pain," "general health," "vitality," "social function," "emotion," "mental health," and mental component summary score subscales of the SF-36. When gender differences were evaluated, the QoL of male patients' spouses changed more when compared with female patients' spouses for all of the WHODAS-II subscales. Colorectal cancer surgery has a significant effect on the QoL of both patients and their spouses, these effects were more significant among male patients' spouses.

\section{CONCLUSION}

Preoperative counseling regarding potential problems should therefore collectively address patient and their spouse as a couple rather than the patient alone, particularly for patients undergoing low anterior resection and abdominoperineal resection procedures.

Key Words: Quality of life; Colorectal surgery; Patients' spouses; Prospective study; Male spouses; Preoperative counseling

CThe Author(s) 2021. Published by Baishideng Publishing Group Inc. All rights reserved.

Core Tip: Although radical surgery for colorectal cancer improves the oncological outcomes, a significant portion of patients suffer from alterations in their quality of life (QoL). There are many studies investigating the QoL of patients who have colorectal cancer but none of these focus on the QoL of spouses. To the best of our knowledge, this is the first prospective and comparative study investigating the QoL following colorectal cancer surgery in both the patients and their spouses during the same time frame. The results of this study showed that patients as well as their spouses QoL was affected following colorectal cancer surgery.

Citation: Aylaz G, Akyol C, Kocaay AF, Gökmen D, Yavuzarslan AB, Erkek AB, Kuzu MA. Quality of life after colorectal surgery: A prospective study of patients compared with their spouses. World J Gastrointest Surg 2021; 13(9): 1050-1062

URL: https://www.wjgnet.com/1948-9366/full/v13/i9/1050.htm

DOI: https://dx.doi.org/10.4240/wjgs.v13.i9.1050

\section{INTRODUCTION}

There is no doubt that radical colorectal surgery improves the oncological outcomes of patients with cancer. However, the literature has clearly documented that social, physical, sexual, and psychological aspects of life, as well as religious worship, are severely impaired after this treatment[1-5]. A significant portion of patients suffer from alterations in their quality of life (QoL), particularly after surgery on distal rectal tumors. Patients who require a stoma or who have low anterior resection (LAR) syndrome may face difficulty adapting to their new anatomy, managing the stoma, defecating, and continuing normal activities in their sociocultural environment. Patients pay an immense price following both sphincter-saving and sphinctersacrificing surgery. Moreover, these psychological and social difficulties, as well as sexual dysfunction, may affect patients' relationships with their spouses, who are generally the primary informal caregivers for patients with cancer. In addition to caring for their sick partners, the spouses also have to deal with their own anxiety, 
P-Reviewer: Nishizawa T, Zyoud $\mathrm{SH}$

S-Editor: Gao CC

L-Editor: A

P-Editor: $\mathrm{Li} \mathrm{JH}$ fatigue, and depression. Previous studies on patients with breast and prostate cancer have also revealed such changes in spouses' QoL7[6-8]. Therefore, both patients' and spouses' QoL should be taken into consideration following surgery for colorectal cancer.

Although there are many studies investigating the QoL of patients who have colorectal cancer[1-5,9] none of these focus on the QoL of spouses. Therefore, we hypothesized that radical rectal cancer surgery affects not only patients' physical, social, and psychological wellbeing but also the QoL of their spouses. The aim of this prospective comparative study was to investigate the QoL of patients and their spouses. To the best of our knowledge, this is the first prospective comparative study to investigate QoL following colorectal cancer surgery in both patients and their spouses during the same time frame.

\section{MATERIALS AND METHODS}

\section{Participant selection}

This prospective study consisted of patients who were married and who underwent surgery at the University of Ankara, Department of Surgery between March 2006 and November 2010. Patients' spouses were also enrolled. The study was approved by the Ethics Committee of the Faculty of Medicine, Ankara University, and all patients provided written informed consent.

\section{Inclusion criteria}

Patient demographics, surgical details, follow-up data, and disease-related data were recorded. To be eligible, patients had to meet the following inclusion criteria: (1) Curative surgery for colorectal adenocarcinoma; (2) Living with a spouse; (3) No other primary malignant tumors; (4) No additional complicating or disabling disease that necessitated nursing assistance (e.g., mental illness); (5) No chemo-radiotherapy within $8 \mathrm{wk}$ prior to the interview; (6) No admittance to a hospital except for stoma closure during the study period (no interview during stoma closure); (7) No major morbidity ( e.g., anastomotic leakage, abdominal sepsis, stoma-related problems, and intensive care unit transfer); (8) No evidence of disease recurrence or metastasis, which was determined at the time of follow-up interviews; (9) Aged over 18 years; and (10) Muslim faith.

\section{Groups}

Patients and their spouses were grouped by the type of surgery they received: Abdominoperineal resection (APR), sphincter-saving resection with an anastomosis within $6 \mathrm{~cm}$ of the anal verge on rigid sigmoidoscopy (LAR), or anterior resection with anastomosis at or above $7 \mathrm{~cm}$, including sigmoid colectomy (AR).

\section{Scales and questionnaires}

Medical outcomes (36-item short form health survey): The 36-item short form health survey (SF-36) was used as a measure of health-related QoL because it is an internationally recognized global measure $[4,10]$. It comprises 36 items that measure perceived health on eight scales (i.e., physical functioning, physical role, bodily pain, general health, vitality, social functioning, emotional role, and mental health) with higher scores (range 0-100) reflecting better perceived health. Additionally, two summary scores can be obtained: The physical component summary score (PCS) and the mental component summary score (MCS). In addition, this tool has been validated in Turkish patients with chronic illnesses, with an internal consistency of 0.92 and a test-retest reliability of 0.94 , which are consistent with published work[11]. Higher SF-36 scores indicate better health-related QoL.

\section{The World Health Organization disability assessment schedule II}

The World Health Organization disability assessment schedule II (WHODAS-II) is an instrument developed by the World Health Organization to assess behavioral limitations and restrictions regarding participation in specific activity domains experienced by an individual independent of their medical diagnosis. The conceptual frame of reference of this instrument is the International Classification of Functioning, Disability, and Health (ICF). Specifically, the instrument is a 36-item, generic, multidimensional questionnaire designed to evaluate the functioning of the individual in six activity domains (i.e., understanding and communicating, getting around, self-care, 
getting along with people, life activities, and participation in society)[5]. This questionnaire has been validated in Turkish patients with chronic illnesses, with an internal consistency of 0.92 and a test-retest reliability of 0.94 , which are consistent with published work[6,7]. A higher WHODAS-II score reflects a higher level of disability.

\section{Ankara university life standards questionnaire}

To identify how surgery affected the life standards of patients and their spouses, a questionnaire was designed by the Department of Public Health, General Surgery and Psychology, Ankara University (Life Standards Questionnaire)[12,13]. It covers the following areas: (1) Employment, including changes in work capability and changes in household chores in daily practice for unemployed women; (2) Social activity; (3) Colostomy care (if applicable); and (4) Religious worship. Religious worship in Muslims was emphasized because their belief structure is particularly affected by the presence of both a stoma and fecal incontinence[13].

\section{Counseling}

Surgical details, possible complications, and temporary or permanent stoma formation were explained preoperatively by the surgeon, and ostomy education was given by the stomatherapist. Religious education and counseling were also performed. Patients had direct access to doctors, the stomatherapist, appliance suppliers, and a religious leader (Imam) at the hospital during the study period.

\section{Interviews}

Patients and spouses were interviewed at the Department of Surgery of Ibni Sina Hospital. The coauthors of the study were trained to administer the questionnaires in a standard fashion and practiced by using the questionnaires on healthy volunteers before the study began. Patients and spouses were interviewed in a private room by a person of the same gender. The same interviewer was used in the preoperative and postoperative period for each patient and spouse, but the interviewer was not blinded to the type of surgery that the patient had undergone. Patients were first asked to complete a demographic questionnaire designed to determine their age, gender, marital status, educational level, income level, and preoperative employment. The SF36, WHODAS-II, and Ankara University Life Standards Questionnaire were administered together and consisted of a total of 92 items, which took approximately $35 \mathrm{~min}$ to $45 \mathrm{~min}$ to complete. Both patients and spouses completed the SF-36, WHODAS-II, and Ankara University Life Standards Questionnaire preoperatively and at postoperative months 15 to 18 .

\section{Statistical analysis}

Statistical analyses were performed with SPSS for Windows 11.5 (SPSS Inc., Chicago, IL, United States). Descriptive statistics were given as the mean \pm SD [median (minimum-maximum)] for metric variables and frequency (percent) for categorical variables. Data from the questionnaires are expressed as the percent change [(postoperative months 15 to 18 - preoperative)/preoperative $\times 100$ ]. To compare two (or more than two) independent groups in terms of metric variables, the MannWhitney $U$ test (or Kruskal-Wallis analysis of variance) was used. When the KruskalWallis test revealed a significant difference between the groups, a multiple comparison test was used to determine which groups differed from each other. Bonferroni correction was used for multiple testing. The Wilcoxon signed-rank test was used to evaluate within-group differences between ordinal variables. For categorical variables, independent groups were compared with the chi-squared test, and dependent groups were evaluated using the McNemar test. The degree of association between ordinal variables was evaluated by Spearman's correlation coefficient. A $P$ value of $<0.05$ was considered statistically significant.

\section{RESULTS}

During this 4.5-year study period, 273 patients with sigmoid or rectal cancer were admitted to the hospital. Of these patients, 119 were eligible and willing to participate. Eleven patients had either systemic or locally inoperable disease, three patients had a severe surgical complication, and five patients were lost to follow-up. Therefore, a total of 100 patients completed the follow-up period. The sociodemographic features of patients and their spouses are shown in Table 1. Correlation of the percentage 
Table 1 Sociodemographic features of patients and their spouses $(n=100)$

\begin{tabular}{|c|c|c|}
\hline Sociodemographic features & Number of patients (male/female) & Number of spouses (male/female) \\
\hline \multicolumn{3}{|l|}{ Type of surgery } \\
\hline APR (male/female) & $33(24 / 9)$ & $33(9 / 24)$ \\
\hline LAR (male/female) & $33(17 / 16)$ & $33(16 / 17)$ \\
\hline AR (male/female) & $34(15 / 19)$ & $34(19 / 15)$ \\
\hline Age (yr) & $57.4 \pm 12.3[57(28-83)]$ & $56.7 \pm 12.1[58(26-85)]$ \\
\hline Gender (male/female) & $56 / 44$ & $44 / 56$ \\
\hline \multicolumn{3}{|l|}{ Educational level } \\
\hline Illiterate & 6 & 12 \\
\hline Primary education & 51 & 41 \\
\hline High school & 26 & 32 \\
\hline College & 17 & 15 \\
\hline \multicolumn{3}{|l|}{ Preoperative employment } \\
\hline Government employee & 7 & 11 \\
\hline Self-employed & 20 & 17 \\
\hline Retired & 37 & 25 \\
\hline Unemployed & 5 & 3 \\
\hline Housewife & 31 & 44 \\
\hline
\end{tabular}

Cells represent frequency except for age, mean \pm SD [median (minimum-maximum)]. APR: Abdominoperineal resection; LAR: Low anterior resection; AR: Anterior resection.

change in quality of life scores between patients and their spouses are shown in Table 2. The surgery groups were comparable with respect to age, gender, preoperative employment status, tumor-node-metastasis stage, and length of postoperative follow-up.

For all the subscales of the WHODAS-II, there was an increase in postoperative disability across all surgery types. This increase in disability was minimal in patients who underwent AR compared with patients who underwent LAR or APR: The LAR group had a significantly greater increase in disability scores for the "getting around" and "life activities" subscales, whereas the AR group had significantly less change in disability scores for the "getting along with people" and "participation in society" subscales and the WHODAS-II total score compared with the other two groups. Similar changes were found for the disability levels of patients' spouses. The "life activities" and WHODAS-II total scores were the least changed in the AR group, whereas the increase in disability level for the "participation in society" subscale was highest in the LAR group (Table 3).

In all the subscales of the SF-36, there was a decrease in the QoL of patients with all surgery types from the preoperative to postoperative period. However, the change in patients' SF-36 scores was significantly lower in the AR group than in the LAR and APR groups. The most significant decrease in QoL scores was detected in the LAR group. Changes in spousal SF-36 scores echoed patients' scores (i.e., they were significantly less changed in the LAR group than in the other groups for the "vitality," "social function," "emotional role," "mental health," "PCS," and "MCS" subscales) (Table 3).

\section{Comparison of the disability and QoL changes in patients and their spouses by gender}

There were increases in the postoperative disability level for all subscales of the WHODAS-II in both genders, but these increases were not statistically significant, except for the "life activities" subscale, which showed a significant increase in female patients and male patients' spouses compared with males, and the "participation in society" subscale, which showed a significant increase in female patients' spouses 


\begin{tabular}{lll}
\hline Scale & Subscale & Spearman's correlation coefficient \\
\hline WHODAS-II & Understanding and communication & 0.183 \\
& Getting around & 0.037 \\
Self-care & $0.349^{\mathrm{b}}$ \\
Getting along with people & 0.189 \\
Life activities & $0.323^{\mathrm{b}}$ \\
Participation in society & $0.312^{\mathrm{b}}$ \\
Total & $0.636^{\mathrm{c}}$ \\
Physical function & 0.071 \\
Role physical & -0.170 \\
Bodily pain & $0.246^{\mathrm{a}}$ \\
GF-36 & $0.233^{\mathrm{a}}$ \\
& PCS & -0.035 \\
Vitality & $0.271^{\mathrm{b}}$ \\
Social function & $0.487^{\mathrm{c}}$ \\
Role emotional & $0.483^{\mathrm{c}}$ \\
Mental health & $0.359^{\mathrm{c}}$ \\
MCS & $0.536^{\mathrm{c}}$ \\
\hline
\end{tabular}

Cells represent Spearman's correlation coefficients.

${ }^{\mathrm{a}} \mathrm{P}<0.05$.

${ }^{\mathrm{b}} P<0.01$.

${ }^{\mathrm{c}} \mathrm{P}<0.001$.

WHODAS-II: World Health Organization Disability Assessment Schedule II; SF-36: 36-item Short Form Survey; PCS: Physical component score; MCS: Mental component score.

(Table 4).

There was a decrease in QoL scores between the preoperative and postoperative measurements for both genders as assessed by the subscales of the SF-36. Although these decreases tended to be greater in female patients, they were not significantly different when compared with the decreases observed among male patients. Regarding the spouses' QoL, similar changes were found in both genders (Table 4).

When the data were analyzed with respect to gender and type of surgery, no significant difference was detected in most of the WHODAS-II and SF-36 scores, with the exception of disability level, which showed higher scores on the "life activities" subscale for the female LAR patient group and on the "understanding and communicating" subscale for the female LAR patients' spouses group.

\section{Ankara university life standards questionnaire}

A comparison of patients' and spouses' feelings regarding their own general health and their QoL preoperatively and 18 mo postoperatively revealed significant decreases in self-rated health and QoL following surgery $(P<0.001)$. This negative effect was observed across all types of surgery, but the most significant decrease was found in the LAR group when compared with the AR group (Table 5). However, there were no gender differences in either the patient group or spouse group for these measures (data not shown).

The time it takes to return to former activities of daily living and work capabilities was increased following APR and LAR, but these increases were not statistically significant (Table 5). Furthermore, no gender differences were detected (data not shown). Patients who underwent either LAR or APR spent more time together with their spouse and more time at home following surgery than patients in the AR group (Table 5). Moreover, male patients' spouses spent significantly more time with their husbands $(P=0.009$; while $71.4 \%$ of male patients' spouses reported that they spent more time with their husbands, only $40.9 \%$ of female patients' spouses said the same) 
Table 3 Comparison of quality of life changes in patients and their spouses according to type of surgery

\begin{tabular}{|c|c|c|c|c|c|c|c|c|c|}
\hline \multirow[t]{2}{*}{ Scale } & \multirow[t]{2}{*}{ Subscale } & \multicolumn{4}{|l|}{ Patient } & \multicolumn{4}{|l|}{ Spouse } \\
\hline & & APR & LAR & AR & $P$ value & APR & LAR & AR & $P$ value \\
\hline \multirow[t]{7}{*}{ WHODAS-II } & Understanding and communication & $16 \pm 29[0(-33 ; 100)]$ & $1 \pm 27[0(-100 ; 50)]$ & $7 \pm 19[0(0 ; 86)]$ & 0.103 & $14 \pm 30[0(0 ; 100)]$ & $15 \pm 53[0(-100 ; 151)]$ & $2 \pm 7[0(0 ; 25)]$ & 0.241 \\
\hline & Getting around & $24 \pm 54[0(-100 ; 200)]$ & $77 \pm 133[46(-100 ; 500)]$ & $10 \pm 26[0(0 ; 100)]$ & $0.001^{1}$ & $8 \pm 27[0(-33 ; 100)]$ & $4 \pm 26[0(-80 ; 100)]$ & $-3 \pm 17[0(-100 ; 11)]$ & 0.467 \\
\hline & Self-care & $4 \pm 19[0(0 ; 100)]$ & $1 \pm 34[0(-100 ; 133)]$ & $2 \pm 13[0(0 ; 75)]$ & 0.830 & 0 & $-3 \pm 18[0(-100 ; 0)]$ & $2 \pm 9[0(0 ; 50)]$ & 0.226 \\
\hline & Getting along with people & $107 \pm 173[50(-100 ; 800)]$ & $64 \pm 70[88(-33 ; 200)]$ & $3 \pm 23[0(-100 ; 50)]$ & $<0.001^{2}$ & $25 \pm 47[0(-100 ; 100)]$ & $53 \pm 67[58(-80 ; 200)]$ & $15 \pm 30[0(0 ; 150)]$ & 0.099 \\
\hline & Life activities & $34 \pm 86[0(-33 ; 400)]$ & $54 \pm 86[0(-100 ; 300)]$ & $11 \pm 71[0(-100 ; 300)]$ & 0.085 & $92 \pm 128[38(0 ; 400)]$ & $128 \pm 210[0(-100 ; 800)]$ & $10 \pm 38[0(-100 ; 100)]$ & $0.013^{2}$ \\
\hline & Participation in society & $84 \pm 66[71(-45 ; 300)]$ & $97 \pm 123[71(-100 ; 550)]$ & $59 \pm 70[47(-58 ; 300)]$ & $0.036^{2}$ & $50 \pm 52[43(-100 ; 200)]$ & $63 \pm 185[13(-100 ; 799)]$ & $38 \pm 36[31(-50 ; 114)]$ & $0.013^{1}$ \\
\hline & Total & $83 \pm 61[57(-41 ; 218)]$ & $112 \pm 150$ [66 (-100; 635)] & $55 \pm 76[29(-57 ; 301)]$ & $0.012^{2}$ & $69 \pm 67[67(-100 ; 349)]$ & $79 \pm 89[59(-95 ; 301)]$ & $34 \pm 40[27(-33 ; 200)]$ & $0.002^{2}$ \\
\hline \multirow[t]{10}{*}{ SF-36 } & Physical function & $-6 \pm 10[-4(-44 ; 12)]$ & $-8 \pm 7[-8(-30 ; 3)]$ & $0 \pm 4[0(-11 ; 15)]$ & $<0.001^{3}$ & $0 \pm 1[0(-7 ; 0)]$ & $2 \pm 12[0(-11 ; 65)]$ & $-1 \pm 4[0(-24 ; 0)]$ & 0.936 \\
\hline & Physical role & $-10 \pm 20[0(-50 ; 14)]$ & $-24 \pm 32[-29(-50 ; 101)]$ & $9 \pm 29[0(0 ; 101)]$ & $<0.001^{3}$ & $0 \pm 14[0(-50 ; 61)]$ & $3 \pm 13[0(-25 ; 33)]$ & $1 \pm 20[0(-50 ; 101)]$ & 0.389 \\
\hline & Bodily pain & $-16 \pm 12[-18(-48 ; 12)]$ & $-20 \pm 15[-19(-53 ; 35)]$ & $-8 \pm 12[-10(-26 ; 24)]$ & $<0.001^{3}$ & $0 \pm 9[0(-19 ; 24)]$ & $-1 \pm 15[0(-27 ; 68)]$ & $-2 \pm 7[0(-31 ; 11)]$ & 0.690 \\
\hline & General health & $-17 \pm 12[-18(-50 ; 0)]$ & $-20 \pm 12[-22(-48 ; 15)]$ & $-10 \pm 8[-13(-21 ; 16)]$ & $0.001^{3}$ & $-3 \pm 4[-2(-18 ; 8)]$ & $-5 \pm 6[-5(-22 ; 7)]$ & $-3 \pm 5[0(-16 ; 0)]$ & 0.077 \\
\hline & PCS & $-10 \pm 11[-8(-45 ; 13)]$ & $-15 \pm 11[-19(-35 ; 11)]$ & $-3 \pm 8[-5(-18 ; 32)]$ & $<0.001^{3}$ & $2 \pm 7[0(-12 ; 18)]$ & $8 \pm 7[9(-4 ; 19)]$ & $-0 \pm 9[0(-30 ; 27)]$ & $<0.001^{1}$ \\
\hline & Vitality & $-7 \pm 10[-5(-43 ; 5)]$ & $-8 \pm 13[-10(-19 ; 54)]$ & $-4 \pm 8[-4(-18 ; 28)]$ & $0.019^{1}$ & $-4 \pm 7[-4(-23 ; 12)]$ & $-6 \pm 16[-5(-21 ; 70)]$ & $-3 \pm 5[0(-16 ; 5)]$ & $0.029^{4}$ \\
\hline & Social function & $-18 \pm 14[-19(-37 ; 16)]$ & $-22 \pm 23[-24(-46 ; 61)]$ & $-10 \pm 17[-13(-47 ; 40)]$ & $0.003^{3}$ & $-11 \pm 13[-12(-38 ; 0)]$ & $-22 \pm 24[-24(-59 ; 61)]$ & $-9 \pm 11[-12(-40 ; 13)]$ & $<0.001^{1}$ \\
\hline & Emotional role & $-18 \pm 38[0(-57 ; 133)]$ & $-39 \pm 39[-57(-57 ; 133)]$ & $11 \pm 39[0(-31 ; 133)]$ & $<0.001^{3}$ & $-3 \pm 36[0(-57 ; 133)]$ & $-30 \pm 39[-47(-57 ; 133)]$ & $3 \pm 25[0(-47 ; 133)]$ & $<0.001^{1}$ \\
\hline & Mental health & $-9 \pm 10-6(-33 ; 19)]$ & $-12 \pm 21[-11(-33 ; 91)]$ & $-6 \pm 9[-5(-31 ; 16)]$ & $0.002^{1}$ & $-7 \pm 11[0(-31 ; 13)]$ & $-8 \pm 25[-10(-36 ; 115)]$ & $-3 \pm 8[0(-31 ; 8)]$ & $0.007^{1}$ \\
\hline & MCS & $-16 \pm 19[-14(-51 ; 44)]$ & $-24 \pm 30[-32(-45 ; 123)]$ & $-4 \pm 12[-5(-23 ; 25)]$ & $<0.001^{3}$ & $-11 \pm 18[-5(-55 ; 28)]$ & $-29 \pm 34[-38(-62 ; 124)]$ & $-4 \pm 10[-3(-33 ; 35)]$ & $<0.001^{1}$ \\
\hline
\end{tabular}

Cells represent the mean \pm SD [median (minimum-maximum)].

${ }^{1}$ Low anterior resection (LAR) is different.

${ }^{2}$ Anterior resection (AR) is different from others.

${ }^{3}$ All are different.

${ }^{4} \mathrm{LAR}$ is different from AR

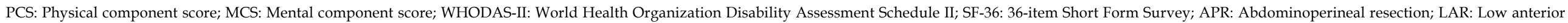
resection; AR: Anterior resection.

and spent more time at home $(P<0.001)$ than female patients' spouses (the proportion of spouses who spent more time at home was $82.1 \%$ and $43.2 \%$ for male patients' spouses and female patients' spouses, respectively). Alterations to the patients' sex 
Table 4 Comparison of the changes in patients' and spouses' quality of life according to gender

\begin{tabular}{|c|c|c|c|c|c|c|c|}
\hline \multirow[b]{2}{*}{ Scale } & \multirow[b]{2}{*}{ Subscale } & \multicolumn{3}{|l|}{ Patient } & \multicolumn{3}{|l|}{ Spouse } \\
\hline & & Male & Female & $P$ value & Male & Female & $P$ value \\
\hline \multirow[t]{7}{*}{ WHODAS-II } & $\begin{array}{l}\text { Understanding } \\
\text { andcommunication }\end{array}$ & $\begin{array}{l}8 \pm 28[0(-100 \\
100)]\end{array}$ & $9 \pm 24[0(-27 ; 86)]$ & 0.829 & $\begin{array}{l}6 \pm 30[0(-100 \\
100)]\end{array}$ & $\begin{array}{l}14 \pm 37[0(-100 ; \\
150)]\end{array}$ & 0.127 \\
\hline & Getting around & $\begin{array}{l}43 \pm 103[0(- \\
100 ; 500)]\end{array}$ & $\begin{array}{l}27 \pm 57[0(-100 \\
300)]\end{array}$ & 0.900 & $\begin{array}{l}5 \pm 29[0(-100 \\
100)]\end{array}$ & $\begin{array}{l}2 \pm 20[0(-80 \\
100)]\end{array}$ & 0.247 \\
\hline & Self-care & $\begin{array}{l}5 \pm 24[0(0 \\
133)]\end{array}$ & $\begin{array}{l}-1 \pm 20[0(-100 \\
75)]\end{array}$ & 0.343 & $\begin{array}{l}-1 \pm 17[0(-100 ; \\
50)]\end{array}$ & $0 \pm 0[0(0 ; 0)]$ & 1.000 \\
\hline & Getting along withpeople & $\begin{array}{l}69 \pm 138[25(- \\
100 ; 800)]\end{array}$ & $\begin{array}{l}38 \pm 66[0(-100 \\
200)]\end{array}$ & 0.317 & $\begin{array}{l}37 \pm 58[17(0 \\
200)]\end{array}$ & $\begin{array}{l}25 \pm 47[0(-100 ; \\
100)]\end{array}$ & 0.322 \\
\hline & Life activities & $\begin{array}{l}8 \pm 47[0(-100 \\
150)]\end{array}$ & $\begin{array}{l}59 \pm 104[0(-100 \\
400)]\end{array}$ & 0.008 & $\begin{array}{l}39 \pm 96[0(-100 \\
350)]\end{array}$ & $\begin{array}{l}101 \pm 174[0(-100 \\
800)]\end{array}$ & 0.046 \\
\hline & Participation insociety & $\begin{array}{l}72 \pm 66[69(- \\
100 ; 240)]\end{array}$ & $\begin{array}{l}91 \pm 112[60(-50 \\
550)]\end{array}$ & 0.593 & $\begin{array}{l}77 \pm 156[37(- \\
17 ; 799)]\end{array}$ & $\begin{array}{l}29 \pm 51[20(-100 \\
200)]\end{array}$ & 0.044 \\
\hline & Total & $\begin{array}{l}74 \pm 85[58(- \\
100 ; 400)]\end{array}$ & $\begin{array}{l}92 \pm 123[44(-12 \\
635)]\end{array}$ & 0.500 & $\begin{array}{l}72 \pm 74[50(-25 \\
301)]\end{array}$ & $\begin{array}{l}51 \pm 66[41(-100 \\
349)]\end{array}$ & 0.453 \\
\hline \multirow[t]{10}{*}{ SF-36 } & Physical function & $\begin{array}{l}-4 \pm 7[-4(-24 \\
15)]\end{array}$ & $-5 \pm 9[0(-44 ; 3)]$ & 0.664 & $\begin{array}{l}-1 \pm 4[0(-24 \\
7)]\end{array}$ & $1 \pm 9[0(-11 ; 65)]$ & 0.237 \\
\hline & Physical role & $\begin{array}{l}-7 \pm 34[0(-50 \\
101)]\end{array}$ & $\begin{array}{l}-10 \pm 26[0(-50 \\
101)]\end{array}$ & 0.833 & $\begin{array}{l}0 \pm 13[0(-50 \\
33)]\end{array}$ & $\begin{array}{l}1 \pm 19[0(-50 \\
101)]\end{array}$ & 0.894 \\
\hline & Bodily pain & $\begin{array}{l}-14 \pm 15[-18(- \\
40 ; 35)]\end{array}$ & $\begin{array}{l}-15 \pm 13[-11(-53 \\
11)]\end{array}$ & 0.842 & $\begin{array}{l}-3 \pm 9[0(-31 \\
22)]\end{array}$ & $0 \pm 12[0(-27 ; 68)]$ & 0.456 \\
\hline & General health & $\begin{array}{l}-15 \pm 12[-14(- \\
36 ; 16)]\end{array}$ & $\begin{array}{l}-16 \pm 11[-14(-50 \\
0)]\end{array}$ & 0.655 & $\begin{array}{l}-3 \pm 5[-0(-22 \\
7)]\end{array}$ & $-4 \pm 5[0(-18 ; 8)]$ & 0.766 \\
\hline & PCS & $\begin{array}{l}-8 \pm 11[-6(-27 \\
32)]\end{array}$ & $\begin{array}{l}-11 \pm 11[-8(-45 \\
7)]\end{array}$ & 0.465 & $\begin{array}{l}3 \pm 9[1(-30 \\
18)]\end{array}$ & $3 \pm 8[1(-15 ; 27)]$ & 0.911 \\
\hline & Vitality & $\begin{array}{l}-6 \pm 11[-7(-22 \\
54)]\end{array}$ & $-7 \pm 8[-4(-43 ; 5)]$ & 0.414 & $\begin{array}{l}-5 \pm 7[-4(-21 \\
6)]\end{array}$ & $\begin{array}{l}-4 \pm 13[-2(-28 \\
70)]\end{array}$ & 0.760 \\
\hline & Social function & $\begin{array}{l}-13 \pm 20[-15(- \\
40 ; 61)]\end{array}$ & $\begin{array}{l}-21 \pm 16[-19(-47 \\
18)]\end{array}$ & 0.090 & $\begin{array}{l}-14 \pm 15[-12(- \\
53 ; 18)]\end{array}$ & $\begin{array}{l}-14 \pm 19-13(-59 \\
61)]\end{array}$ & 0.615 \\
\hline & Emotional role & $\begin{array}{l}-15 \pm 50[0(-57 \\
133)]\end{array}$ & $\begin{array}{l}-15 \pm 34[0(-57 \\
133)]\end{array}$ & 0.447 & $\begin{array}{l}-14 \pm 23[0(-57 ; \\
23)]\end{array}$ & $\begin{array}{l}-7 \pm 44[0(-57 \\
133)]\end{array}$ & 0.832 \\
\hline & Mental health & $\begin{array}{l}-8 \pm 18[-11(-33 \\
91)]\end{array}$ & $\begin{array}{l}-10 \pm 10[-7(-33 \\
4)]\end{array}$ & 0.613 & $\begin{array}{l}-8 \pm 11[-6(-31 \\
7)]\end{array}$ & $\begin{array}{l}-5 \pm 19[-5(-36 \\
115)]\end{array}$ & 0.674 \\
\hline & MCS & $\begin{array}{l}-14 \pm 27[-16(- \\
44 ; 123)]\end{array}$ & $\begin{array}{l}-15 \pm 16[-10(-51 \\
25)]\end{array}$ & 0.542 & $\begin{array}{l}-17 \pm 18[-6(- \\
61 ; 2)]\end{array}$ & $\begin{array}{l}-14 \pm 28[-8(-62 \\
124)]\end{array}$ & 0.955 \\
\hline
\end{tabular}

Cells represent the mean \pm SD [median (minimum-maximum)] of the percentage change in score between the preoperative value and the postoperative value at 15-18 mo for each subject. WHODAS-II: World Health Organization Disability Assessment Schedule II; SF-36: 36-item Short Form Survey; PCS: Physical component score; MCS: Mental component score.

lives were significantly more common following LAR and APR than AR (Table 5). Regarding the religious worship of patients, praying and fasting activities were decreased after surgery; these decreases were significant in the LAR and APR groups compared with the AR group. There were no changes in the praying and fasting activities of spouses (Table 5). The fulfillment of religious activities decreased in male patients compared with female patients (data not shown).

\section{DISCUSSION}

The evaluation of the consequences of diseases and treatments on patient-reported outcomes, such as QoL, has gained extensive attention[8,13-17]. In fact, the diagnosis of cancer and the associated treatment process have considerable social, physical, psychological, and sexual impacts for both patients and their spouses. Little information is available regarding spouses' QoL following colorectal cancer surgery. 
Table 5 Evaluation of the Ankara University Life Standards Questionnaire according to the type of surgery

\begin{tabular}{|c|c|c|c|c|c|c|c|c|}
\hline & Patient & & & & Spouse & & & \\
\hline Questions & APR & LAR & AR & $\begin{array}{l}P \\
\text { value }\end{array}$ & APR & LAR & AR & $\begin{array}{l}P \\
\text { value }\end{array}$ \\
\hline General health status $^{1}$ & $\begin{array}{l}0.58 \pm 0.97[1(- \\
2 ; 2)]\end{array}$ & $\begin{array}{l}0.75 \pm 0.51[1 \\
(0 ; 2)]\end{array}$ & $\begin{array}{l}0.18 \pm 0.72[0(- \\
2 ; 2)]\end{array}$ & 0.002 & $\begin{array}{l}0.42 \pm 0.66[0 \\
(0 ; 2)]\end{array}$ & $\begin{array}{l}0.66 \pm 0.75[1(- \\
1 ; 2)]\end{array}$ & $\begin{array}{l}0.15 \pm 0.44[0(- \\
1 ; 1)]\end{array}$ & 0.006 \\
\hline General quality of life $\mathrm{e}^{1}$ & $\begin{array}{l}0.76 \pm 0.71[1(- \\
1 ; 2)]\end{array}$ & $\begin{array}{l}0.81 \pm 0.59[1 \\
(0 ; 2)]\end{array}$ & $\begin{array}{l}0.50 \pm 0.66[0 \\
(0 ; 2)]\end{array}$ & 0.068 & $\begin{array}{l}0.48 \pm 0.71[0(- \\
1 ; 2)]\end{array}$ & $\begin{array}{l}1.06 \pm 0.84[1 \\
(0 ; 3)]\end{array}$ & $\begin{array}{l}0.32 \pm 0.77[0(- \\
2 ; 2)]\end{array}$ & 0.001 \\
\hline $\begin{array}{l}\text { Time to return to old life and } \\
\text { activity (mo })^{2}\end{array}$ & $\begin{array}{l}4.17 \pm 1.37[5 \\
(0 ; 5)]\end{array}$ & $\begin{array}{l}4.03 \pm 1.52[5 \\
(0 ; 5)]\end{array}$ & $\begin{array}{l}3.70 \pm 1.16[4 \\
(1 ; 5)]\end{array}$ & 0.077 & $\begin{array}{l}4.07 \pm 1.14[4 \\
(0 ; 5)]\end{array}$ & $\begin{array}{l}3.57 \pm 1.75[4 \\
(0 ; 5)]\end{array}$ & $\begin{array}{l}3 \pm 1.53[3(0 ; \\
5)]\end{array}$ & 0.018 \\
\hline \multicolumn{9}{|l|}{$\begin{array}{l}\text { Amount of time spent with } \\
\text { spouse }^{3}\end{array}$} \\
\hline Unchanged & $6(18.2)$ & $10(31.3)$ & $21(61.8)$ & & $5(15.2)$ & $5(15.6)$ & $22(64.7)$ & \\
\hline Decreased & $8(24.2)$ & - & $8(23.5)$ & & $4(12.1)$ & $1(3.1)$ & $5(14.7)$ & \\
\hline Increased & $19(57.6)$ & $22(68.8)$ & $5(14.7)$ & $<0.001$ & $24(72.7)$ & $26(81.3)$ & $7(20.6)$ & $<0.001$ \\
\hline \multicolumn{9}{|l|}{ Amount of time spent at home ${ }^{3}$} \\
\hline Unchanged & $5(15.2)$ & $8(25)$ & $26(76.5)$ & & $4(12.1)$ & $4(12.5)$ & $21(61.8)$ & \\
\hline Decreased & $3(9.1)$ & - & $3(8.8)$ & $<0.001$ & $3(9.1)$ & $1(3.1)$ & $2(5.9)$ & $<0.001$ \\
\hline Increased & $25(75.8)$ & $24(75)$ & $5(14.7)$ & & $26(78.8 \%)$ & $27(84.4)$ & $11(32.4)$ & \\
\hline \multicolumn{9}{|l|}{ Sex life ${ }^{3}$} \\
\hline Unchanged & $13(39.4)$ & $18(56.3)$ & $32(94.1)$ & $<0.001$ & $20(60.6)$ & $19(59.4)$ & $31(91.2)$ & 0.005 \\
\hline Unavailable & $20(60.6)$ & $14(43.8)$ & $2(5.9)$ & & $13(39.4)$ & $13(40.6)$ & $3(8.8)$ & \\
\hline \multicolumn{9}{|l|}{ Praying $^{3}$} \\
\hline Unchanged & $13(46.4)$ & $17(68)$ & $26(100)$ & $<0.001$ & 27 (96.4) & $25(96.2)$ & $22(100)$ & NA \\
\hline Decreased & $15(53.6)$ & $8(32)$ & - & & $1(3.6)$ & $1(3.8)$ & - & \\
\hline \multicolumn{9}{|l|}{ Fasting $^{3}$} \\
\hline Unchanged & $10(35.7)$ & $16(64)$ & $24(92.3)$ & $<0.001$ & 25 (89.3\%) & $25(96.2)$ & $22(100)$ & NA \\
\hline Decreased & $18(64.3)$ & $79(36)$ & $2(7.7)$ & & $3(10.7)$ & $1(3.8)$ & - & \\
\hline \multicolumn{9}{|l|}{ Purifying aims ${ }^{3}$} \\
\hline Unchanged & $22(78.6)$ & $18(72)$ & $25(96.2)$ & 0.064 & 27 (96.4) & $25(96.2)$ & $22(100)$ & NA \\
\hline Decreased & $6(21.4)$ & $7(28)$ & $1(3.8)$ & & $1(3.6)$ & $1(3.8)$ & - & \\
\hline
\end{tabular}

${ }^{1}$ Cells represent the mean $\pm \mathrm{SD}$ [median (minimum-maximum)] of the percentage change in score between the preoperative value and the postoperative value at $15-18$ mo- for each subject.

${ }^{2}$ mean \pm SD [median (minimum-maximum)].

${ }^{3}$ Frequency (percent).

APR: Abdominoperineal resection; LAR: Low anterior resection; AR: Anterior resection.

Depending on the localization of the colorectal carcinoma, either sphincter-saving or sphincter-sacrificing radical surgery can be performed. All procedures have a significant impact on patients' QoL. The stoma itself can disrupt rectal function owing to the presence of a low anastomosis. Moreover, significant sexual and urological dysfunction has also been reported, mainly due to damage to the autonomic pelvic nerve plexus[1]. Colorectal cancer diagnosis and treatment are not isolated experiences [18]. Spouses are the most frequent providers of support to patients with colorectal cancer. Patients with cancer and their caregivers (e.g., spouses) experience emotional distress, physical problems, psychological difficulties, and sexual problems related to changes in their life[19,20]. The present study aimed to evaluate the QoL following surgery for colorectal cancer, namely, AR, LAR, and APR, in both patients and their spouses during the same time frame.

The present study revealed a significant relationship between the disability levels of patients and their spouses in terms of both the total score and subscales (self-care, life 
activities, and participation in society) of the WHODAS-II. There were also positive correlations between the QoL of patients and their spouses for most of the subscales (bodily pain, general health, vitality, social function, emotional role, mental health, and MCS) of the SF-36. When the evaluations were conducted separately for each surgical procedure, there was an increase in postoperative disability levels in patients for all surgery types; however, the level of disability was minimal in patients following AR when compared with patients who underwent LAR or APR. Similarly, there was a decrease in the patient QoL for all surgery types during the postoperative period as measured by all subscales of the SF-36. However, this deterioration was minimal in the AR group when compared with the LAR and APR groups.

As hypothesized, we found decreases in the QoL scores over time in the spouses of patients with colorectal cancer when measured with the SF-36, specifically in the "vitality," "social function," "emotional role," "mental health," and MCS subscales. Additionally, we found an increase in spousal disability over time for the "life activity" and "participation in society" subscales and the total score of the WHODASII. Similarly, Badger et al[21] showed that $25 \%$ of partners often suffer the same or higher levels of emotional distress compared with cancer survivors. In fact, cancer treatment, with its collateral side effects, produces physical and emotional disturbances that influence QoL. A study by Graça Pereira et al[3], which compared different modes of treatment (i.e., surgery, surgery plus chemotherapy, or surgery followed by radiotherapy) in colorectal cancer, demonstrated that patients who received only surgery had lower levels of depression, anxiety, and traumatic stress symptoms when compared with patients who received surgery plus chemotherapy or surgery plus radiotherapy. Similar results were found for the spouses of patients undergoing these treatments.

Previous studies on changes in the QoL of spouses of patients with breast and prostate cancer have not explored gender-related differences in QoL, as doing a gender-based comparison is only meaningful in gender nonspecific cancers such as colorectal cancer[2,22,23]. In the present study, there was an increase in postoperative disability for all subscales of the WHODAS-II for both genders, but these increases were not statistically significant except for the "life activities" subscale, which showed a significant increase the score among female patients and male patients' spouses. The "participation in society" subscale also showed a significant increase among female patients' spouses.

The results of the Ankara University Life Standards Questionnaire show that patients' and spouses' perceptions of their own general health and general QoL significantly decreased following patients' surgeries. Many studies in the literature have compared patients who underwent LAR with patients who underwent APR, and the general consensus in these publications is that there exists a possibility of LAR syndrome in patients with very low-level anastomosis, which has a negative effect on QoL. In these patients, constipation, diarrhea, frequent stools, and the development of fecal incontinence is a major problem that decreases QoL[24-26]. In our study, when the types of surgery were compared, there was a distinct deterioration in the LAR group. However, there were no gender differences between the patients and spouses. We found that patients and their spouses tended to spend more time together and at home following surgery, especially in the LAR and APR groups. Interestingly, we found that male patients' spouses spent significantly more time with their husbands and spent more time at home than female patients' spouses. This situation significantly impacts the lifestyle of male patients' spouses. As mentioned previously by Cakmak et al[27], this may be because male patients are more willing to have their colostomy care managed by their wives. Changes in sex life were significantly more common following LAR and APR than in the AR group.

With regard to the religious attitudes of patients, the literature suggests that religion is an important factor in coping with cancer[28,29]. Shaheen $\mathrm{Al}$ Ahwal et al [28] found that religiosity is associated with fewer depressive symptoms and fewer suicidal thoughts in Muslim patients with colorectal cancer. We found that religious activities, such as praying and fasting, decreased significantly in the LAR and APR groups when compared with the AR group, whereas there were no changes in praying and fasting in spouses. This is probably because of the importance of cleanliness and the desire to be free of any fecal material, especially when praying in Islam. We also found that fulfillment of religious duties decreased more among male patients than among female patients.

Although the present study has shown valuable findings, its design is not without certain flaws. The main limitations could be counted as followed: The first concern is to include the patients who underwent AR for sigmoid colon cancer. AR is a different type of surgery compared to LAR and APR. It is already known that these patients 
have better functional and sexual outcomes. Another limitation is about the exclusion criterias; patients with major morbidity were excluded from the study. Complications are an unavoidable aspect of colorectal surgery. It may be better to eveluate the effects of major complications in QoL scoring.

\section{CONCLUSION}

Colorectal cancer surgery has a significant effect on the QoL of both patients and their spouses, with a greater impact on male patients' spouses. Preoperative counseling regarding potential problems should therefore collectively address the patient and their spouse as a couple rather than the patient alone, particularly for patients undergoing LAR and APR procedures.

\section{ARTICLE HIGHLIGHTS}

\section{Research background}

We hypothesized that colorectal cancer surgery affects not only the patient's physical, social, and psychological aspects of lifestyle, but also the quality of life (QoL) of the patient's spouse.

\section{Research motivation}

Although there are many studies investigating the QoL in patients who have colorectal cancer none of these focus on the spousal QoL. To the best of our knowledge, this is the first prospective and comparative study investigating the QoL following colorectal cancer surgery in both the patients and their spouses during the same time frame.

\section{Research objectives}

The aim of this prospective and comparative study was to investigate the QoL of patients and their spouses.

\section{Research methods}

Patients who remained well a minimum of 5 years after curative surgery for colorectal carcinoma and their spouse's as well were included in this prospective study. Both patients ( $n: 100)$ and their spouses $(n: 100)$ filled SF-36 (Medical Outcome Study 36item Short Form Survey) and WHODAS-II (World Health Organization-Disability Assessment Schedule II) preoperatively (preop), and postop 15-18 mo.

\section{Research results}

There were statistically significant positive correlations between the disability scores of both patients and their spouses for the "self-care", "life activities" and "participation in society" subscales of WHODAS II and the total score for WHODAS II $(P<0.01$; for each). There were also positive correlations between the life quality of both patients and their spouses in most of the subscales of SF-36. Statistically significant correlations were found for "bodily pain", "general health", "vitality", "social function", "role emotional", "mental health" and MCS subscales of SF-36 ( $P<0.05$; for each). When the gender differences were evaluated, it was found that the QoL of female spouses changed more than male spouses for all subscales of WHODAS-II.

\section{Research conclusions}

Patients as well as their spouses QoL was affected following colorectal cancer surgery. These changes detected more significantly in female spouses.

\section{Research perspectives}

Randomized controlled trials are expected to be conducted to measure the effect of counseling of the patients with colorectal cancer and their spouses.

\section{REFERENCES}

1 Calpista A, Lai S, Agostini A, Mancini M, Artibani W. Functional urological complications after 
colo-rectal cancer surgery. Pelviperineology 2007; 26: 38-40

2 Duggleby W, Doell H, Cooper D, Thomas R, Ghosh S. The quality of life of male spouses of women with breast cancer: hope, self-efficacy, and perceptions of guilt. Cancer Nurs 2014; 37: E28-E35 [PMID: 23348665 DOI: 10.1097/NCC.0b013e31827ca807]

3 Graça Pereira M, Figueiredo AP, Fincham FD. Anxiety, depression, traumatic stress and quality of life in colorectal cancer after different treatments: A study with Portuguese patients and their partners. Eur J Oncol Nurs 2012; 16: 227-232 [PMID: 21783416 DOI: 10.1016/j.ejon.2011.06.006]

4 Ware JE Jr, Sherbourne CD. The MOS 36-item short-form health survey (SF-36). I. Conceptual framework and item selection. Med Care 1992; 30: 473-483 [PMID: 1593914]

5 World Health Organization. 2018 WHO disability assessment schedule II (WHODAS-II). [cited 15 March 2021]. In: World Health Organization [Internet]. Available from: https://www.who.int/standards/classifications/international-classification-of-functioning-disabilityand-health/who-disability-assessment-schedule

6 Kutlay S, Küçükdeveci AA, Elhan AH, Oztuna D, Koç N, Tennant A. Validation of the World Health Organization disability assessment schedule II (WHODAS-II) in patients with osteoarthritis. Rheumatol Int 2011; 31: 339-346 [PMID: 20020133 DOI: 10.1007/s00296-009-1306-8]

7 Küçükdeveci AA, Kutlay Ş, Yıldızlar D, Öztuna D, Elhan AH, Tennant A. The reliability and validity of the World Health Organization Disability Assessment Schedule (WHODAS-II) in stroke. Disabil Rehabil 2013; 35: 214-220 [PMID: 22671861 DOI: 10.3109/09638288.2012.690817]

8 Rubin GP, Devlin HB. The quality of life with a stoma. Br J Hosp Med 1987; 38: 300-303, 306 [PMID: 3315080]

9 Pachler J, Wille-Jørgensen P. Quality of life after rectal resection for cancer, with or without permanent colostomy. Cochrane Database Syst Rev 2005; CD004323 [PMID: 15846707 DOI: 10.1002/14651858.CD004323.pub3]

10 Brazier JE, Harper R, Jones NM, O'Cathain A, Thomas KJ, Usherwood T, Westlake L. Validating the SF-36 health survey questionnaire: new outcome measure for primary care. BMJ 1992; 305: 160164 [PMID: 1285753 DOI: 10.1136/bmj.305.6846.160]

11 Pinar R. Quality of life in diabetic patients, Doctoral Dissertation. Istanbul, Turkey: University of Istanbul, 1995

12 Celasin H, Karakoyun R, Yllmaz S, Elhan AH, Erkek B, Kuzu MA. Quality of life measures in Islamic rectal carcinoma patients receiving counselling. Colorectal Dis 2011; 13: e170-e175 [PMID: 21651692 DOI: $10.1111 / j .1463-1318.2011 .02649 . x]$

13 Kuzu MA, Topçu O, Uçar K, Ulukent S, Unal E, Erverdi N, Elhan A, Demirci S. Effect of sphinctersacrificing surgery for rectal carcinoma on quality of life in Muslim patients. Dis Colon Rectum 2002; 45: 1359-1366 [PMID: 12394435 DOI: 10.1007/s10350-004-6425-4]

14 Devlin HB, Plant JA, Griffin M. Aftermath of surgery for anorectal cancer. Br Med J 1971; 3: 413418 [PMID: 5566622 DOI: $10.1136 / \mathrm{bmj} .3 .5771 .413$ ]

15 Engel J, Kerr J, Schlesinger-Raab A, Eckel R, Sauer H, Hölzel D. Quality of life in rectal cancer patients: a four-year prospective study. Ann Surg 2003; 238: 203-213 [PMID: 12894013 DOI: 10.1097/01.sla.0000080823.38569.b0]

16 Essink-Bot ML. Health status as a measure of outcome of disease and treatment. Humanitas. Rotterdam, The Netherlands: Erasmus University Rotterdam, 1995

17 Sprangers MA, Taal BG, Aaronson NK, te Velde A. Quality of life in colorectal cancer. Stoma vs. nonstoma patients. Dis Colon Rectum 1995; 38: 361-369 [PMID: 7720441 DOI: 10.1007/bf02054222]

18 Silva AL, Monteiro PS, Sousa JB, Vianna AL, Oliveira PG. Partners of patients having a permanent colostomy should also receive attention from the healthcare team. Colorectal Dis 2014; 16: O431O434 [PMID: 25104405 DOI: 10.1111/codi.12737]

19 Ozturk O, Yalcin BM, Unal M, Yildirim K, Ozlem N. Sexual dysfunction among patients having undergone colostomy and its relationship with self-esteem. J Family Med Com Health 2015; 2: 1028

20 Traa MJ, Braeken J, De Vries J, Roukema JA, Orsini RG, Den Oudsten BL. Evaluating quality of life and response shift from a couple-based perspective: a study among patients with colorectal cancer and their partners. Qual Life Res 2015; 24: 1431-1441 [PMID: 25429822 DOI: 10.1007/s11136-014-0872-8]

21 Badger T, Segrin C, Dorros SM, Meek P, Lopez AM. Depression and anxiety in women with breast cancer and their partners. Nurs Res 2007; 56: 44-53 [PMID: 17179873 DOI: 10.1097/00006199-200701000-00006]

22 Alacacioglu A, Yavuzsen T, Dirioz M, Yilmaz U. Quality of life, anxiety and depression in Turkish breast cancer patients and in their husbands. Med Oncol 2009; 26: 415-419 [PMID: 19031014 DOI: 10.1007/s12032-008-9138-z]

23 Kim Y, Kashy DA, Wellisch DK, Spillers RL, Kaw CK, Smith TG. Quality of life of couples dealing with cancer: dyadic and individual adjustment among breast and prostate cancer survivors and their spousal caregivers. Ann Behav Med 2008; 35: 230-238 [PMID: 18365297 DOI: 10.1007/s12160-008-9026-y]

24 Bretagnol F, Troubat H, Laurent C, Zerbib F, Saric J, Rullier E. Long-term functional results after sphincter-saving resection for rectal cancer. Gastroenterol Clin Biol 2004; 28: 155-159 [PMID: 15060460 DOI: $10.1016 / \mathrm{s} 0399-8320(04) 94870-1]$

25 Kakodkar R, Gupta S, Nundy S. Low anterior resection with total mesorectal excision for rectal cancer: functional assessment and factors affecting outcome. Colorectal Dis 2006; 8: 650-656 [PMID: 
16970574 DOI: 10.1111/j.1463-1318.2006.00992.x]

26 Ortiz H, Armendariz P. Anterior resection: do the patients perceive any clinical benefit? Int $J$ Colorectal Dis 1996; 11: 191-195 [PMID: 8876278 DOI: 10.1007/s003840050042]

27 Cakmak A, Aylaz G, Kuzu MA. Permanent stoma not only affects patients' quality of life but also that of their spouses. World J Surg 2010; 34: 2872-2876 [PMID: 20706836 DOI: 10.1007/s00268-010-0758-z]

28 Shaheen Al Ahwal M, Al Zaben F, Sehlo MG, Khalifa DA, Koenig HG. Religious beliefs, practices, and health in colorectal cancer patients in Saudi Arabia. Psychooncology 2016; 25: 292-299 [PMID: 25990540 DOI: 10.1002/pon.3845]

29 Balboni TA, Vanderwerker LC, Block SD, Paulk ME, Lathan CS, Peteet JR, Prigerson HG. Religiousness and spiritual support among advanced cancer patients and associations with end-of-life treatment preferences and quality of life. J Clin Oncol 2007; 25: 555-560 [PMID: 17290065 DOI: 10.1200/JCO.2006.07.9046] 


\section{DS \\ Baishideng ${ }^{\circledR}$}

Published by Baishideng Publishing Group Inc

7041 Koll Center Parkway, Suite 160, Pleasanton, CA 94566, USA

Telephone: +1-925-3991568

E-mail: bpgoffice@wignet.com

Help Desk: https:/ /www.f6publishing.com/helpdesk

https://www.wjgnet.com

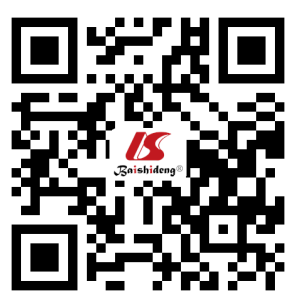

